\title{
The Mediating Effect of Organizational Trust on Human Resource Management and Affective Commitment
}

\author{
Sharmin Shahid (Corresponding author) \\ Graduate School of Business, Universiti Kebangsaan Malaysia, \\ Bangi, Selangor, Malaysia \\ E-mail: sharmin@ukm.edu.my \\ Zaher Zain \\ Graduate School of Business, Universiti Kebangsaan Malaysia, \\ Bangi, Selangor, Malaysia \\ E-mail: zaher.zain@ukm.edu.my
}

Syed Shah Alam

Faculty of Economics and Management, Universiti Kebangsaan Malaysia,

Bangi, Selangor, Malaysia

E-mail: shahalam@ukm.my

Received: Oct. 18, 2017 Accepted: Nov. 7, $2017 \quad$ Online published: Nov. 15, 2017 doi:10.5296/ijhrs.v8i1.12006

URL: https://doi.org/10.5296/ijhrs.v8i1.12006

\begin{abstract}
This research empirically examines the mediating role of organizational trust on human resource management, and affective commitment. An independent variable may not provide the significant effect on a dependable variable whereas, the effect may be found significant through a third variable or indirect relationship. Thus, the research paradigm is determining the function of indirect variable whether it role as a full mediator or a partial mediator in the relationship analysis. The study is based on human resource management, employee psychology and organizational behavior literature, hypotheses were tested by using Baron
\end{abstract}


and Kenny's mediating analysis. The study reported mixed results on research key variables. Theoretically, the study contributes to conceptualized human resource management practices affective commitment and organizational trust theory. It also provides practitioners' implications and awareness that lack of organizational trust, employee affective commitment might be reduced and management can be failure to accomplish organizational success and managerial acumen.

Keywords: affective organizational commitment, human resource management, mediating analysis, organizational trust

\section{Introduction}

Organizational phenomenon revealed the most critical things are to manage human resource smoothly. In spite of that organizational stability and employee harmony is essential to the global approaches of human resource management (HRM). The foremost dilemma of an organization is the failure in managing human resource and maintaining harmony within employment relationships (Nik Mutasim et al. 2011). Consequently, organizational trust and affective commitment is vital to HRM practices like employee training, rewards, job security, selection, and performance appraisal. Similarly, information sharing ability, communication system, and allowing employees in decision making process are determined the extent of liberal HRM practices. Eventually, if employees' feels that they are being appreciated as valuable assets not as a commodity and management respect to their opinion in all aspects certainly they will demonstrate high trusting behavior and high affective commitment toward their assigned job (Azmi 2010).

The research focuses on the theoretical and empirical gaps with respect to study variables. Theoretically, HRM can be interpreted as a continuous advance process of evaluating HR needs, find people to fill those needs, match between work and organizational perspective, and minimize organizational economic and non-economic failure rate (Kingshott 2007). While it gives emphasis on improving affective commitment and trust at the workplace. Aspects of HRM practices are also influenced by factors of social, economic, technological events and cultural diversity. Certainly, different background employee comes at the workplace with different psychology. Thus, to build up the smooth relationships between employee to employee, and employee to management is difficult. If management ignores the human issues, they have difficulty to understand why employees often lack enthusiasm in their work although operationally it is correct (Chapman 2004). Therefore, the elaborate study of HRM is signifies and requires particularly, organizational trust as a mediator might be able to more interesting and knowledgeable (Joarder et al. 2012).

The mediator variables describe the significant information on the method, reason and the situation of a phenomenon that occurred. However, many researches have failed to accurately test mediator variables some of them did not even use the right terminologies and jargons to test the mediator (Suradi et al. 2009). Hence, the purpose of the study is to test the mediating effect of research variables by using appropriate theory and method which may produce more empirical support and knowledge in respective area. Thus, the significance of the study aspires to contribute with theory, methodology and for the practitioners by adding further 
knowledge, better understanding and empirical evidence on HRM literature.

\section{Problem Statement and Objectives}

The nature of human beings is unpredictable and to understand human behavior and employee's psychology is complex. Because of employee perceptions differ from person to person, time, and place (Mueller 2008). Thus, managing HR is more crucial. If organization does not plan for HR may find to difficult to meet its personnel obligations and consequently fail to meet its overall performance (Tan 2008). Moreover, the challenge of globalization, and massive change in cultural diversity forced management to become more practical and competitive. Principally, managerial negligence influence to reduce employee affection and trust toward their organizations. Since, it is required that the rules, regulations, and practices of HRM should be employee oriented which reduce their work-related stress (Yilmaz 2008).

The broad research questions are whether there is sufficient managerial capacity, competency and efficient HRM practices to face with the needs of employee's psychological issues like affective commitment and organizational trust. If not, what are the circumstances to make HRM practices failure, and what should be done to improve the relationships among the variables? Therefore, the objectives of the study are to identify, explore and investigate the mediating effect of organizational trust whether it is a full mediator, partial mediator or is not a mediator on the relationships between aspects of HRM practices and affective commitment.

\section{The Research Paradigm}

Human resource management is an integrated strategy and planned development process for effective utilization of human resource for the achievement of organizational goals (Snell et al. 2011). The perspective of HRM practices is to 'build' $H R$ rather than acquiring or allocating (Wright et al. 2008). This approach highlights firstly, the importance of ensuring the rationality and consistency across a range of HR practices. Secondly, speed up the implementation or adopt a strategic change in HRM practices if required. Moreover, HRM strategy regarding selection, performance appraisal, rewards, and training is a multi-stage and multi-level process. These are serious challenging issues for upcoming business organizations and essentially, the management has to overcome it. To generalize the effectiveness and efficiency of HRM practices, Pfeffer (2005) suggests that there is no one best way to manage people. Management that adapt most successfully to the new social and economic doctrine is characterized by a similar set of HR practices.

To ensure high affective commitment and high performance HRM practices have to develop, manage, and motivate employees' activities and needs (Storey 2007). The concepts assume that HR offer organizations an edge, and managing organizational philosophy i e. culture, beliefs, and values is more important than procedures and systems. Employee commitment is more important than simple compliance and jobs need to be designed to allow devolved responsibility and empowerment. While, HRM practices uncovered seven underlying functions staffing, training, rewards, job security, performance appraisal, participation in decision making, and communication and information sharing to enhance affective commitment. 


\section{MInstitute Macrothink $^{\text {Int }}$}

International Journal of Human Resource Studies

ISSN 2162-3058

Trust is a basic organizing principle of interpersonal exchange relationships. In the commitment-trust relationship the descriptions of trust are the belief in the integrity, character, and ability of the management. The reciprocal faith in one's intentions and behaviors and a confidant reliance on the integrity, honesty, and justice can create a culture of organizational trust (Morgan et al. 2010). In this light, there is obviously a need to integrate trust into daily organizational processes and operations in particular the HRM practices (Lamsa et al. 2006). Theoretically, HRM practices for instance may improve employees' self-regulation and motivate them to act in an expected, responsible, reliable, loyal and truthful way at least in employment relationships. Organizational trust refers the rational trust of an individual employee with respect to the process of acquiring knowledge, perceptions, and experience toward his or her colleague, management and organization itself. Essentially, HR management can address and take some initiative to build up or develop employees' organizational trust. Since, organizational trust is not inherited it can be established through appropriate HRM practices (Tan et al. 2009).

\section{The Conceptual Framework}

The conceptual model demonstrates the direct relationships between aspects of HRM practices and affective organizational commitment, and organizational trust, the direct relationships between organizational trust and affective commitment; and the indirect path involves the role of organizational trust as the mediator on the relationship between research variables. The direct and indirect paths discuss in the following hypotheses. The proposed conceptual model is:

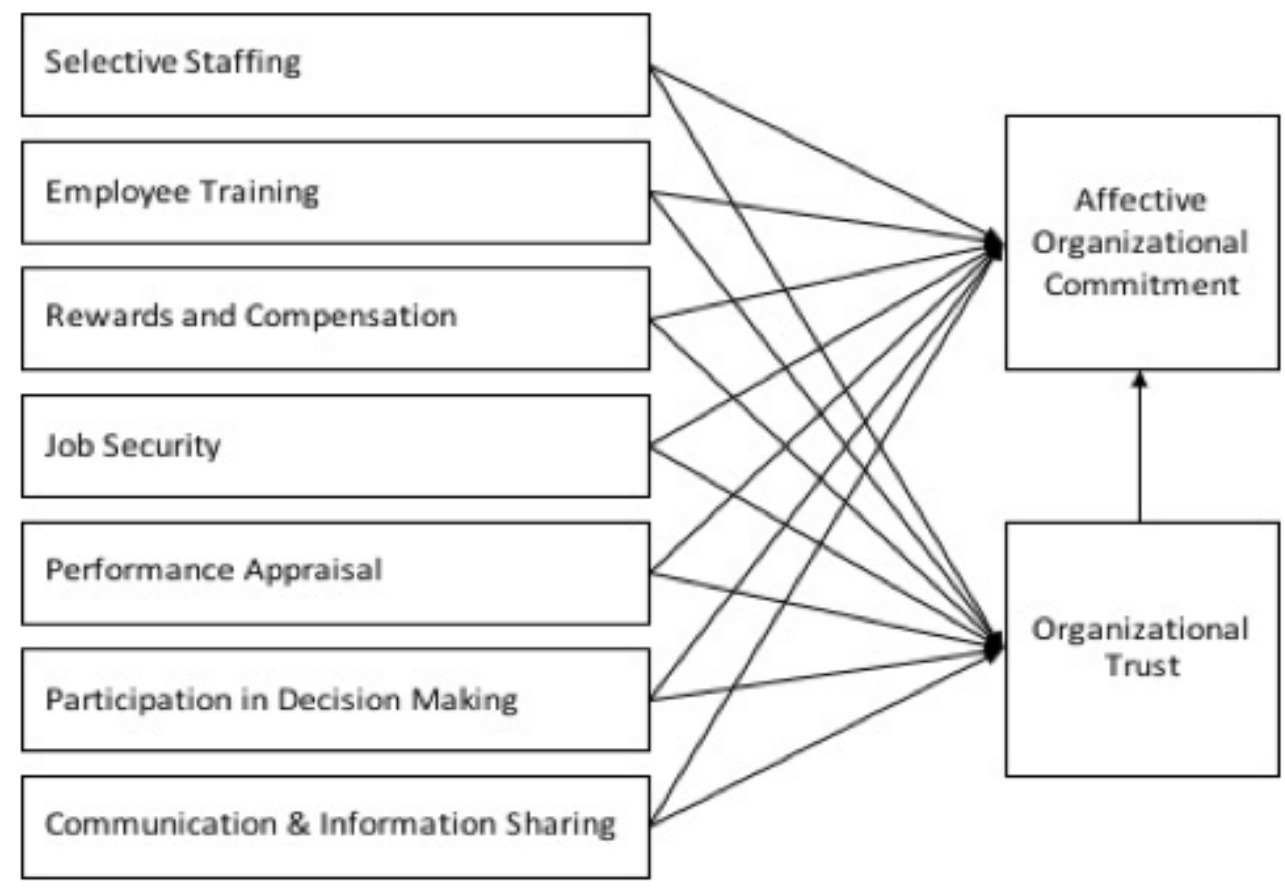

Figure1. The Research Model 


\subsection{Selective Staffing}

The relationship between selective staffing concerned to find the universally and generally best conduct of employees' affective commitment. Empirical studies have found that affective commitment can work well synergistically or more than expected result if HR management is able to select the right person for the right job at beginning of staffing process (Pfeffer 2010; Fathi et al. 2011). Selective staffing is vital component to build the first impression for the employees to be more trusted in management and organization. When employees have positive feelings that organization practices a good staffing process and management select the best candidates for the empty position their degree of trust in organization is demonstrate high (Obeidat et al. 2014). Consistent with the above findings from the relevant literature, this study proposes the following hypothesis:

Hypothesis 1: Organizational trust mediates the relationships between staffing and affective commitment.

\subsection{Employee Training}

Organizations that extensively train their employees be able to create a reputation for valuing and developing employee's perceptions and skills towards achieving organizational success (Joarder et al. 2011). Empirical study by Obeidat et al. (2014) noted that employee training is investment instead of cost of an organization. The more employees are trained, their work quality improve, and feels career settled which facilitated to enhance affective committed toward organization. To improve the organizational productivity and profitability employee training is important. Employee training and trust in organization is positively related and significant. Meyer \& Smith (2000) suggested that the influence of training, and affective commitment was largely mediated by organizational trust. Therefore, the following hypothesis is suggested:

Hypothesis 2: Organizational trust strengthens the relationships between employee training and affective commitment.

\subsection{Rewards and Compensation}

Inequity exists when employee feels the ratio of their outcomes to inputs and the ratio of other's outcomes to other's inputs are unequal. Herein, inputs represent individual's time, effort, knowledge, and experience that he or she gives to the organization as an employee. On the other hand, outputs refer to the benefits that employees received from their employers such as wages, salary, compensation and rewards. Indeed, inequity in workplace is a source of employee job dissatisfaction. Pfeffer (2010) have found positive and significant correlation between equitable reward system and employee affective commitment. A trust climate creates an atmosphere where, management expects to gain high employee performance as they rewarded accordingly. Thus, equitable rewards and compensation is positively and significantly related with organizational trust. Empirically, Tzafrir (2005) recorded partial meditating effect on the relationship between the variables. Thus, the propose hypothesis is:

Hypothesis 3: Organizational trust mediates the relationship between rewards and 
compensation and affective organizational commitment.

\subsection{Job Security}

Job security can decrease employee turnover intention, and increase employee's emotional attachment, strong sense of belongingness to spend their career with the organization (Samuel et al. 2009). Several researchers emphasize the significance of employee job security. For example, Pfeffer (2010) considered employment security as one of the best practices. The higher the level of job security among employees' they would be more committed to their work. Most of the time, the major problems arise by the fear for job loss. When management can ensure secured employees career, job position, and future that means they can achieve employees trust in organization. Additionally, Wong et al. (2002) noted trust in organization explain significant correlations, and mediates the relationships between job security and affective commitment. Consequently, this study suggests the following hypothesis:

Hypothesis 4: Organizational trust strengthens the relationship between job security and affective organizational commitment.

\subsection{Performance Appraisal}

Efficient measure of individual performance is one of the major tasks of HRM. Theoretical and empirical literature provides strong evidence on the relationship between performance appraisal and affective commitment. Snell et al. (2011) reported that performance management is an integrated process of HR planning, monitoring, developing, rating and rewarding system to accomplish organizational outcomes. Employees who are affectively committed toward organization tend to perform better than those who are not. Likewise, employees who are committed to organizational goals are likely to work harder and more consistent with organizational expectations than those who are not. Indeed, high levels of employee's performance appraisal are the result of high levels of affective commitment. Employees trust in organization is directly related to their performance appraisal. If management gives enough attention, honor and addresses employee performance then the trust level of employees become high and they feel important, increase job involvement, and self-motivate to achieve their organizational goals. Beside on social exchange theory, Tan et al. (2009) reported trust in organization significantly and fully mediates the relationships between trust in co-worker and affective commitment. Neves et al. (2009) found trust in supervisor fully mediates the relationships between affective commitment and employee performance. Hence, the proposed hypothesis is:

Hypothesis 5: Organizational trust mediates the relationship between performance appraisal and affective organizational commitment.

\subsection{Participation in Decision Making}

Based on social exchange relationship employees' have rights to participate in decision making and problem-solving procedure in an organization (Wilkinson et al. 2010). These rights help to strengthen employee and management relationship. Employee who feels obligations or responsibilities towards organization are more committed and close to 
accomplishes organizational objectives. In addition, employees' participation in decision making helps to increase their work motivation and willingness to job involvement. Participation in decision making can satisfy needs of human growth self-actualization and job satisfaction which influence employee's affective commitment. Empirical studies by Han et al. (2010) have shown positive correlations between participation in decision making and affective commitment and suggested for more empirical research. Since, trust is a key instrument of management to coordination and control employees. Management supposes to be trust employees and allow them to participate in organizational decision-making process. In fact, managers take risks when they increase employees' power in decision making. However, the philosophy behind this practice is to make sense for the employees that they are not just a commodity but very essential resource to improve and enhance employees trust in organization (Obeidat et al. 2014). Thus, this study is proposed:

Hypothesis 6: Organizational trust mediates the relationship between participation in decision making and affective organizational commitment.

\subsection{Communication and Information Sharing}

Organizational success depends on skilled communication systems. It's management responsibility to be honest and supportive to practices two-way communication systems (Lee et al. 2010) as well as informed the rules, regulations, standard and organizational results to the employees which also provide the openness of managerial practices (Conway et al. 2008). Empirical studies by Liu et al. (2007) have proven that communication and information sharing has direct positive correlations with affective commitment. Additionally, fair communication and information sharing influence to enhance trust, building employee self-worth and perceptions toward organizations. This implies that information sharing should promote and increase perceptions of fairness on the nature of decisions and the processes by which decisions are made. Albrecht et al. (2003) reported trust partially mediates the relationships between communication and commitment. Literature confirms that communication and information sharing strongly relates with trust in management (Tzafrir et al. 2004). Consistent with this literature, this study proposes the following hypothesis:

Hypothesis 7: Organizational trust mediates the relationship between communication and information sharing and affective commitment.

\subsection{Organizational Trust and Affective Organizational Commitment}

Trust plays a complex role in organization. It has been referred to as the emotional glue that binds the management and organizations to their employees (Williams et al. 2005). However, organizational trust is not a permanent fixture. It can be lost through one careless mistake by management (Cook et al. 2006). Moreover, organizational trust and affective organizational commitment are essential for organizational short-term success \& long-term efficacy (Hunt et al. 2009). The success or failure of any organization is directly and positively related to the level of existence of organizational trust within it; as well as the extent to which it is appropriately handled by the daily managerial practices (Huff et al. 2003). Organizational trust facilitates the effects of other determinants on desired outcomes i e., employee 
commitment, satisfaction, and high performance. Likewise, Morgan et al. (2010) support this statement and added that organizational trust influence employees' decision, and intention to stay organization which leads to develop affective commitment. Empirically, researchers' e g. Tzafrir (2004), Joarder et al. (2011), and Mayer et al. (2005), reported that trust lead to the higher level of affective commitment and the relationships between the variables is statistically significant. In the light of above discussions, it seems to be logical to expect the relationship between trust and affective commitment to be as follows:

Hypothesis 8: Employee organizational trust will be significantly and positively related to affective organizational commitment.

\section{Research Methodology}

The purpose of a research design is to ensure the evidence obtained is enables to answer the research questions as unambiguously as possible (David 2004). To achieve the research objectives this study adopts a positivist paradigm and a cross-sectional research design. Moreover, this design has been employed to discover the degrees to which variables relate to each other or testing the study hypotheses (Bryman 2007). Furthermore, cross sectional research design was used more effectively to interpret the causal process of a phenomenon as well as to understand the correlation and the mediating role of the research variables (Bauman et al. 2002).

\subsection{Population}

The population of the study is officers, executives, and top-level managers of bank employees in Bangladesh. The purpose of the study settings is the growth rate of banks in Bangladesh helps to develop the total economy (Bangladesh Bank Report 2012). Thus, managing these organizations would be very challenging and significance in near future (Absar et al. 2011).

\subsection{Data Collection}

The data for this study were obtained through the distribution of a self-administered structured questionnaire to bank employees. In the data collection period researcher took helps from personal contacts and requested to help in terms of collect the fill up questionnaires and send it back to the researcher. About 676 questionnaires were received out of them only 499 questionnaires were usable for further analyses. The survey questionnaire consists of a cover letter. Essentially, section A of the questionnaire measure aspects of HRM practices; section $\mathrm{B}$ consists of organizational trust; section $\mathrm{C}$ consists to measure affective commitment.

\subsection{Measuring Instrument}

The measures of the study were adopted from the literature on HRM practices, and organizational behaviour. All statements the respondents were requested to rate their level of agreement with the statements using 7 -point scales $(7=$ strongly agree and $1=$ strongly disagree). Out of seven HRM practices, the measures for selective staffing 7 items, training 8 items, performance appraisal 9 items, and rewards and compensation 7 items are adopted 
from Snell and Dean's (1992) with some minor modifications. The rest i. e., job security, participation in decision making, and communication and information sharing 5, 4, 6 items are adopted from Boselie et al. (2001) respectively. Affective organizational commitment 8 items are adopted from Meyer and Allen's (1991). While, 12 items of organizational trust adopted from Ferres et al. (2003).

\subsection{Test of Reliability}

Statistically the concept of reliability refers to the degree of accuracy of the estimate of the true score in a population of objects to be measured. A good estimate of reliability coefficient is important as it provides a useful index of the extent to which results of the instrument can be trusted in basic research. Reliability is often measured by the Cronbach's Coefficient Alpha (Nunnally 1978) which is a test of the consistency of respondents to all the sample items in a measure. The study used Cronbach Coefficient Alpha to assess the reliability of a measurement scale with multi-scale items.

The Cronbach's alpha coefficient of selective staffing (SS), employee training (ET), rewards and compensation (RC), job security (JS), performance appraisal (PA), participation in decision making (PDM), communication and information sharing (CIS) were 0.81, 0.88, 0.90, $0.80,0.88,0.87$, and 0.82 respectively. While the coefficient for the mediating variable organizational trust (OT) was 0.90 , the score for the dependent variable affective organizational commitment (AOC) was 0.86. Given the scores for all variables exceed the cut-off value of 0.70 ; the high reliability coefficient indicates high internal consistency among its statements (Nunnally, 1978). It can be concluded that the measures for all the variables were reliable. Two major methods were used in order to determine the presence of multicollinearity among independent variables of the study. These methodologies involved to measure of both a Tolerance test (SS: 0.84, ET: 0.96, RC: 0.93, JS: 0.84, PA: 0.91, PDM: 0.86, and CIS: 0.73) and Variance Inflation Factor (VIF) is (SS: 1.18, ET: 1.03, RC: 1.06, JS: 1.18, PA: 1.09, PDM: 1.15, and CIS: 1.36). On the existence of Multicollinearity, the Pearson's Correlations Tolerance test of Variance Inflation Factor (VIF) registered for all the variables are less than 10. Hair (2010) suggests that for VIF score less than 10; no multicollinearity exists in the data set. The study result shows VIF range from 1.034 to 1.363 , as it is well below 10 confirms there were no any auto correlations problem in the independent variables and no muticollinearity indicate at the data set.

\subsection{Test for Construct Validity: Content, Concurrent and Convergent Validity}

Data validity refers to the extent to which a scale or set of measures accurately represents the concept of interest or observation (Hair et al. 2010). This study performed several validity tests i e. content validity, face validity, concurrent validity, and convergent validity. The content validity as an integrated evaluative judgment of the degree to which an empirical evidence and theoretical rationales support the adequacy and the appropriateness of inferences and actions based on test scores (Samuel et al. 1998). This concept determination is subjective and judgmental (Nunnally 1978).

The study questionnaire is constructed based on extensive literature review and opinions of 
scholars in the HRM and organizational behavior studies. Thus, it complies the content and face validity. According to Charles (1969) a concurrent and convergent validity test refers to the concepts and measurements that are supposed to be related. Convergent validity is employed as evidence of correlations between the key variables and their theoretical and empirical relationships (Tabachnick et al. 2007). By testing the research hypotheses, the convergent validity is ensured. Essentially, the results of the reliability analyses ensure the concurrent validity of the research.

Table 1. Result of Total Variance Explained of Factors

\begin{tabular}{c|c|c|c|c|c|c|c|c|c}
\hline \multirow{2}{*}{ Factor } & \multicolumn{3}{|c|}{ Initial Eigenvalues } & \multicolumn{2}{c|}{$\begin{array}{c}\text { Extraction Sums of Squared } \\
\text { Loadings }\end{array}$} & \multicolumn{3}{c}{$\begin{array}{c}\text { Rotation Sums of Squared } \\
\text { Loadings }\end{array}$} \\
\cline { 2 - 11 } & Total & $\begin{array}{c}\text { \% of } \\
\text { Variance }\end{array}$ & $\begin{array}{c}\text { Cumulative } \\
\%\end{array}$ & Total & $\begin{array}{c}\text { \% of } \\
\text { Variance }\end{array}$ & $\begin{array}{c}\text { Cumulative } \\
\%\end{array}$ & Total & $\begin{array}{c}\text { \% of } \\
\text { Variance }\end{array}$ & $\begin{array}{c}\text { Cumulative } \\
\%\end{array}$ \\
\hline 1 & 7.552 & 16.418 & 16.418 & 7.071 & 15.371 & 15.371 & 4.250 & 9.240 & 9.240 \\
\hline 2 & 4.462 & 9.700 & 26.118 & 4.012 & 8.721 & 24.092 & 4.101 & 8.915 & 18.155 \\
\hline 3 & 4.111 & 8.937 & 35.054 & 3.644 & 7.921 & 32.013 & 4.055 & 8.816 & 26.971 \\
\hline 4 & 3.474 & 7.552 & 42.606 & 3.033 & 6.594 & 38.607 & 2.853 & 6.201 & 33.172 \\
\hline 5 & 2.564 & 5.574 & 48.180 & 2.077 & 4.514 & 43.122 & 2.755 & 5.990 & 39.162 \\
\hline 7 & 2.253 & 4.897 & 53.077 & 1.785 & 3.880 & 47.001 & 2.609 & 5.671 & 44.833 \\
\hline
\end{tabular}

According to Field (2005) reliability and validity of exploratory research design depends on reliability of factor loadings and sample size. Generally, over 300 cases are probably adequate but communalities and eigenvalues after extraction should probably be above 0.5 . Table 1 demonstrated seven factors loaded from the data set Factor 1: PA (16.41\%), Factor 2: RC (9.70\%), Factor 3: ET (8.93\%), Factor 4: SS (7.55\%), followed by Factor: 5, 6, 7 are CIS (5.57\%), PDM (4.8\%) and JS (4.16\%) respectively. 57.25\% variance is explained of total variance which presents high coefficient correlation and convergent validity among the research variables. The eigenvalues of seven HRM practices are statistically significant the cut-off value which is more than 0.5 .

\section{Results}

\subsection{Data Analysis}

Multivariate data analysis should be suitable as data is collected on more than one variable, and these variables are correlated with each other. By employing multivariate statistical techniques, these variables and their statistical dependence is taken into consideration (Hair et al. 2010). The Statistical Package for the Social Sciences (SPSS) is employed for data cleaning, screening and data analysis. It enables to identify and deal with missing data. According to Tabachnick et al. (2007) dealing with 5\% or less random pattern missing value will work from a large data set.

The moderator variable determines the time of taking effect and explains the mechanism and reasons behind the effect. The study employed Baron and Kenny's (1986) model to measure the mediator relationships. According to the model, a variable can be classified as a mediator 
under following conditions: (a) there exists a significant relationship between IV and mediator; (b) there exists a significant relationship between DV and mediator; and (C) there exists a significant relationship between the IV and DV. If any one of the above conditions not fulfilled, then there exists no mediating effect. Therefore, the variable is not considered as a mediating variable.

As noted earlier, in this study aspects of HRM practices, affective commitment, and organizational trust are IV, DV and Mediating variables respectively. Hence, the mediator formula is:

1. Equation: $\mathrm{IV}+\mathrm{DV} \rightarrow \mathrm{C}$

2. Equation: $\mathrm{IV}+\mathrm{Me}(\mathrm{DV}) \rightarrow \mathrm{a}$

3. Equation: $\mathrm{Me}(\mathrm{IV})+\mathrm{DV} \rightarrow \mathrm{b}$

4. Equation: $\mathrm{Me}+$ individual IV (IV) $+\mathrm{DV} \rightarrow \mathrm{c}^{\prime}$

Table 2. Mediating Results of OT on the aspects of HRM practices and AOC

\begin{tabular}{|c|c|c|c|c|c|c|c|c|}
\hline IV & DV & Equation & $\mathrm{B}$ & SE B & Beta & $\begin{array}{c}\mathrm{t} \\
\text { Value }\end{array}$ & Sig & $\mathrm{R}^{2}$ \\
\hline 1. SS & $\mathrm{AOC}$ & $\mathrm{C}$ & 0.303 & 0.045 & 0.289 & 6.737 & 0.000 & 0.084 \\
\hline 2. SS & $\mathrm{OT}$ & A & 0.363 & 0.041 & 0.373 & 8.959 & 0.000 & 0.139 \\
\hline 3. OT & $\mathrm{AOC}$ & B & 0.445 & 0.044 & 0.415 & 10.166 & 0.000 & 0.172 \\
\hline 4. $\mathrm{SS}$ & $\mathrm{AOC}$ & $c^{\prime}$ & 0.163 & 0.045 & 0.156 & 3.595 & 0.000 & 0.193 \\
\hline $\mathrm{OT}$ & & & 0.383 & 0.047 & 0.357 & 8.205 & 0.000 & \\
\hline 1. ET & $\mathrm{AOC}$ & $\mathrm{C}$ & 0.119 & 0.043 & 0.122 & 2.742 & 0.006 & 0.015 \\
\hline 2. ET & $\mathrm{OT}$ & A & 0.067 & 0.041 & 0.073 & 1.638 & 0.102 & 0.005 \\
\hline 3. OT & $\mathrm{AOC}$ & B & 0.445 & 0.044 & 0.415 & 10.166 & 0.000 & 0.172 \\
\hline 4. ET & $\mathrm{AOC}$ & $c^{\prime}$ & 0.090 & 0.040 & 0.092 & 2.262 & 0.024 & 0.181 \\
\hline $\mathrm{OT}$ & & & 0.438 & 0.044 & 0.408 & 10.015 & 0.000 & \\
\hline 1. $\mathrm{RC}$ & $\mathrm{AOC}$ & $\mathrm{C}$ & 0.115 & 0.040 & 0.128 & 2.881 & 0.004 & 0.016 \\
\hline 2. $\mathrm{RC}$ & $\mathrm{OT}$ & A & 0.143 & 0.037 & 0.171 & 3.859 & 0.000 & 0.029 \\
\hline 3. OT & $\mathrm{AOC}$ & B & 0.445 & 0.044 & 0.415 & 10.166 & 0.000 & 0.172 \\
\hline 4. $\mathrm{RC}$ & $\mathrm{AOC}$ & $c^{\prime}$ & 0.053 & 0.037 & 0.059 & 1.429 & 0.154 & 0.176 \\
\hline OT & & & 0.434 & 0.044 & 0.405 & 9.784 & 0.000 & \\
\hline 1. JS & $\mathrm{AOC}$ & $\mathrm{C}$ & 0.250 & 0.040 & 0.272 & 6.301 & 0.000 & 0.074 \\
\hline 2. JS & $\mathrm{OT}$ & A & 0.278 & 0.036 & 0.325 & 7.664 & 0.000 & 0.106 \\
\hline 3. OT & $\mathrm{AOC}$ & B & 0.445 & 0.044 & 0.415 & 10.166 & 0.000 & 0.172 \\
\hline 4. JS & $\mathrm{AOC}$ & $c^{\prime}$ & 0.141 & 0.039 & 0.153 & 3.595 & 0.000 & 0.193 \\
\hline $\mathrm{OT}$ & & & 0.392 & 0.046 & 0.365 & 8.560 & 0.000 & \\
\hline 1. PA & $\mathrm{AOC}$ & $\mathrm{C}$ & 0.487 & 0.037 & 0.507 & 13.109 & 0.000 & 0.257 \\
\hline 2. PA & $\mathrm{OT}$ & A & 0.234 & 0.039 & 0.262 & 6.048 & 0.000 & 0.069 \\
\hline 3. OT & $\mathrm{AOC}$ & B & 0.445 & 0.044 & 0.415 & 10.166 & 0.000 & 0.172 \\
\hline 4. $\mathrm{PA}$ & $\mathrm{AOC}$ & $c^{\prime}$ & 0.410 & 0.036 & 0.428 & 11.333 & 0.000 & 0.342 \\
\hline $\mathrm{OT}$ & & & 0.325 & 0.040 & 0.303 & 8.031 & 0.000 & \\
\hline 1. PDM & $\mathrm{AOC}$ & $\mathrm{C}$ & 0.198 & 0.034 & 0.250 & 5.754 & 0.000 & 0.062 \\
\hline 2. PDM & $\mathrm{OT}$ & A & 0.255 & 0.031 & 0.345 & 8.204 & 0.000 & 0.119 \\
\hline 3. OT & $\mathrm{AOC}$ & B & 0.445 & 0.044 & 0.415 & 10.166 & 0.000 & 0.172 \\
\hline 4. PDM & $\mathrm{AOC}$ & $c^{\prime}$ & 0.096 & 0.034 & 0.121 & 2.802 & 0.005 & 0.185 \\
\hline $\mathrm{OT}$ & & & 0.400 & 0.046 & 0.373 & 8.638 & 0.000 & \\
\hline 1. CIS & $\mathrm{AOC}$ & $\mathrm{C}$ & 0.402 & 0.041 & 0.403 & 9.826 & 0.000 & 0.163 \\
\hline 2. CIS & OT & A & 0.505 & 0.035 & 0.543 & 14.422 & 0.000 & 0.295 \\
\hline 3. OT & $\mathrm{AOC}$ & B & 0.445 & 0.044 & 0.415 & 10.166 & 0.000 & 0.172 \\
\hline 4. CIS & $\mathrm{AOC}$ & $c^{\prime}$ & 0.252 & 0.047 & 0.252 & 5.335 & 0.000 & 0.217 \\
\hline OT & & & 0.298 & 0.051 & 0.278 & 5.871 & 0.000 & \\
\hline
\end{tabular}




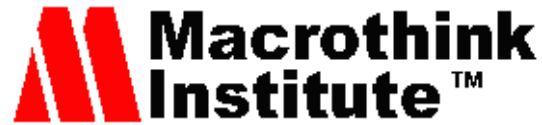

Table 2 shows the mediating effects of OT on the relationship between SS and AOC. SS is significantly related to AOC (equation $\mathrm{C}$ : $\beta=0.303, \mathrm{p}<0.000$ ). While equation ' $\mathrm{a}$ ' tells us SS as IV significantly influence OT, $(\beta=0.363, p<0.000)$; based on equation ' $b$ ' OT as IV significantly influence on AOC as DV $(\beta=0.445, p<0.000)$. Finally, based on equation c', SS and OT as IVs significantly influence AOC as DV. According to Newson (2005) if all the regression relationships are significant from equation 1 to $3(\mathrm{C}, \mathrm{a}, \mathrm{b})$ and there is a decrease in the $B$ value in equation 4 compared to equation 1 (when IV i e., SS is controlled over another IV i e., OT value is $\beta=0.163$ ); the findings suggest an existence of a partial mediation.

The mediating effect of OT on the relationship between ET and AOC is presented in Table 2. Based on equation ' $C$ ' the $B$ is 0.119 ; whereas, in equation ' $a$ ' $B$ value is $0.067, p>0.05$ insignificant relationship between ET as IV and OT as DV. Although equation ' $b$ ' and equation c' is showing significant, according to Baron and Kenny (1986), if one or more of these equation relationships are not significant, researchers usually conclude that the mediation is not possible. The results show steps 1 to 3 are not significant, therefore, the findings suggest for no mediation of OT on the relationships between ET and AOC.

In the Table 2 denotes the mediating effects of OT on the relationships of RC and AOC. Three equations $i$ e., in equation ' $C$ ' ( $\beta$ value is 0.115 ), equation ' $a$ ' and ' $b$ ' ( $\beta$ is 0.143 and 0.445 accordingly) indicate significant relationships. However, for equation $c$ ' the relationships are insignificant $(B=0.053, \mathrm{p}>0.05)$. According to Newson (2005), if there are significant relationships from steps 1 to 3 , but in step 4 is not significant the findings suggests for full mediation. Hence, the results demonstrate the full mediation effect of OT on the relationship between $\mathrm{RC}$ and AOC.

From the Table 2 illustrates the effects of OT as mediating variable on the relationship between JS and AOC. Based on equation ' $\mathrm{C}$ ', JS is shown to be significantly related to AOC (equation $C$ : $\beta=0.250, p<0.000$ ). In equation ' $a$ ' JS as IV significantly influence OT as the DV $(\beta=0.278, p<0.000)$. While in equation ' $b$ ' OT as IV significantly influence AOC as DV $(\beta=0.445, p<0.000)$, in equation c', JS and OT as IVs significantly influence AOC. Given that all the regression relationships are significant in equations $\mathrm{C}, \mathrm{a}, \mathrm{b}$; and there is a decrease in the $B$ value in equation 1 as opposed to equation 4 (IV i e., JS is controlled over another IV $\mathrm{i}$ e., OT value is $B=0.141$ ); the findings, hence suggest an existence of a partial mediation.

The mediating outcome of OT on the relationship between PA and AOC is demonstrated in Table 2. Based on equation ' $C$ ', $P A$ is shown to be significantly related to AOC (equation C: $B$ $=0.487, \mathrm{p}<0.000)$. While in equation ' $\mathrm{a}$ ', PA as IV significantly influence OT as DV $(\beta=$ $0.234, \mathrm{p}<0.000)$, in equation ' $\mathrm{b}$ ' OT as IV significantly influence AOC as DV ( $\beta=0.445, \mathrm{p}$ $<0.000$ ). Finally, in equation c' PA and OT as IVs are significantly related to AOC as DV. As noted earlier, if all the regression relationships are significant from equation 1 to $3(\mathrm{C}, \mathrm{a}, \mathrm{b})$ and there is a decrease in the $\beta$ value in equation 1 as compared to equation 4 (if IV $\mathrm{i}$ e., PA is controlled over another IV i e., OT value is $\beta=0.410$ ); the finding suggests for a partial mediation (Wong et al. 2002). 
Table 2 also presents the results of the mediating test of OT on the relationships between PDM and AOC. In the equation ' $C$ ', the IV PDM is significantly related to AOC (equation $C: \beta=0.198, p<0.000)$. In equation ' $a$ ' $P D M$ as IV is recorded as significantly related to OT as DV $(\beta=0.255, p<0.000)$, while based on equation ' $b$ ', OT as IV significantly influence AOC as DV $(\beta=0.445, p<0.000)$. In equation $c '$, PDM and OT as IVs significantly influence AOC as DV. Since, all the regression relationships are significant from equation 1 to $3(\mathrm{C}, \mathrm{a}, \mathrm{b})$ and the $B$ value in equation 1 is lower than in equation 4 (IV $\mathrm{i}$ e., PDM is controlled over another IV $\mathrm{i}$ e., OT value is $B=0.096$ ); the results confirm the partial mediation relationships between the variables (Albrecht et al. 2003).

Additionally, Table 2 confirms the effects of OT as mediating variable on the relationship between CIS and AOC. Based on equation ' $\mathrm{C}$ ' (equation C: $\beta=0.402, p<0.000$ ), CIS is significantly related to AOC; and in equation ' $a$ ', CIS as IV also significantly influence OT as DV $(\beta=0.505, p<0.000)$. While in equation ' $b$ ' OT as IV significantly influence AOC as DV $(\beta=0.445, p<0.000)$. In equation c', CIS and OT as IVs significantly influence AOC as DV $(B=0.298, p<0.000)$; and there is a decrease in the $\beta$ value in equation 1 as compared to equation $4(\beta=0.252)$. Thus, the results suggest for a partial mediation between the variables (Suradi et al. (2009).

Furthermore, the table 2 presented the result of relationship between OT and AOC, in equation ' $b$ ' $(\beta=0.445, p<0.000)$, and t value is 10.16 which is statistically significance at $99 \%$ confidence level.

\section{Discussion}

\subsection{Selective Staffing}

Trust presents the confidence level of one individual employee has in another employee or entity to act in a fair, ethical, and expected manner. It signifies an exchange relationship underlying the act, belief, and confidence at the employment relationships. The finding suggests staffing partial mediates on the relationship between trust and affective commitment. It refers selecting the best and talented employee is the core to establish employees' faith believes and trust at the very beginning of their work life. Hence, staffing constitutes an important part of social exchange relationships in organization which characterize the essential components of affective commitment and trust. Whereas, Neves et al. (2009) had hypothesized that trust is full mediate the relationship between selective staffing and commitment.

\subsection{Employee Training}

The study finding suggests that employee training statistically significant relate to affective commitment and insignificant with organizational trust. Therefore, the study result confirms no meditation effect of training on the relationships between the dependent and mediating variable respectively. The respondents of the study feel that HR management are failed to build employee trust by their training system. They believe organization is not effective and efficient to designed training program appropriately. Moreover, they demonstrate that management take training as a cost instead of investment. Furthermore, miss match between 
training program and the selective person are the causes behind to decrease their trust. Empirically, Suradi et al. (2009) found similar result when they test the mediating effect of training on the relationship of service quality and employee satisfaction.

\subsection{Rewards and Compensation}

Rewards and compensation fully mediates on the relationship between trust and affective commitment. The result illustrates that employee reward and compensation individually statistically significant on affective commitment and organizational trust. However, when organizational trust measures as a controlled or mediating role on the respective variables then it found significant with affective commitment but not with trust. Indeed, the respondents realized that their reward and compensation packages are not sufficient if they compare with other banks. In addition, the salary, incentives, and bonus may not that much standard to match with their needs and demands. As a result, they show low affective commitment and insignificance organizational trust. Joarder et al. (2012) had found the results of partial mediation effects testing the relationship on trust in supervisor, reward and compensation, and affective commitment.

\subsection{Job Security}

Employee perceptions on affective commitment oriented work system effect on trust and job security (Boselie, et al. 2001). The high level of job security can reduce employee turnover intention and enhance job involvement with high level of affective commitment and trust. Theoretically, organizational trust partially mediates on the relationship between job security and affective commitment. The present results consistent with the previous studies by Witte et al. (2003) and Tzafrir (2004) reported partial mediation effect of trust on the relationship between job security and affective commitment. Whereas, Joarder et al. (2012) noted employee turnover intention full mediates on the relationship between job security and affective commitment.

\subsection{Performance Appraisal}

Commitment-performance relationship may still be an important component of organizational dynamics. The concept of a performance culture is influence to improve the contribution of individuals to the overall success of organization. The higher affective commitment is a predictor of the employees' superior performance and strengthens toward employees' trust (Gong et al. 2009). While, Neves et al. (2009) reported that trust as a full mediation effects on staffing toward performance appraisal and affective commitment. However, the mediation result of the present research is reported that trust partially mediates on the relationship between performance appraisal and affective commitment.

\subsection{Participation in Decision Making}

The study hypothesized that trust partially mediates on participation in decision making and affective commitment. The result of the study shows similar with the theoretical concepts. Thus, the findings accepted the research hypothesis. Theoretically, the most important concept of social exchange theory is the reciprocate exchange relationship between employee 
and management, which is ensure by the employee participation in decision making process. The thoughts of HR managers at that moment focused on promoting employee participation in decision making process. Indeed, they believed that by giving employee opportunity to be more engaged in decision making their sense of belongingness, job involvement, and job satisfaction will be leading to lower turnover (Han 2010). However, the current results could not be verified with the existing result due to unavailability of empirical evidence on the relationship between the research variables.

\subsection{Communication and Information Sharing}

From the social exchange point of view, the study hypothesizes trust partially mediates on communication and information sharing, and affective commitment. The research findings accepted the hypothesis. Trust appears to be essential intangible resources in organization which bond management and employee relationships to enhance affective commitment through convenient communication and information sharing system. The extent to which organizations are demonstrate to employees that they are cared for, valued, and properly informed of organizational information. All these facilitate a stronger perception of trust and affective commitment. Tazfrir et al (2004) noted trust as full mediation on communication and procedural justices. Whereas, Chiang et al. (2011) founded trust no mediates on information sharing and employee commitment.

\subsection{Organizational Trust and Affective Organizational Commitment}

Organizational trust and affective commitment is one of the significance areas that HR management needs to be more concerned. Since, highly committed employees have a high degree of psychological involvement toward their jobs, which makes them work hard to accomplish organizational interests (Mueller 2008). The result also confirms this concept. Trust is statistically significant and directly positive toward affective commitment. Thus, the hypothesis is accepted. The respondents perceived positive feelings on the variables. They believe that organizations' problem is their own problem management shows their integrity to communicate and take actions, they can trust their management and coworkers, as a whole they feel emotionally attached a part of family and a strong sense of belongingness to their organization. The empirical evidence from previous studies by Tzafrir (2004) and Joarder et al. (2011) have found the significant coefficient correlation between the variables.

\section{Limitations and Future Directions}

Likewise, several empirical studies, this study is not without of its limitations. Eventually, these limitations require to further discussions. Firstly, the study settings concentrate on banks officers and executives at Bangladesh in developing country concern. Thus, the future study may be eligible to conduct in same study settings or public and private sector in different geographical area. Secondly, the study is focused on mandatory HRM practices. However, the future study settings may demand for some other variables as independent $\mathrm{i}$ e. performance management, service quality enhancement, employee retention, and HRIS. The dimensions of commitment may be investigated like attitudinal, behavioral, normative, and multidimensional approach for further research directions. Finally, the study employed the 
mediating variable and was not extended to investigate the effect of moderating on the direct relationships. In behavioral science, there are some other potential constructs such as job-related attitudes, managerial role, organizational culture, and job stress those may be employ as mediator/moderator as the new study area of future research. Nevertheless, the study identifies needs for empirical studies on HRM practices and organizational behavior encompasses longitudinal studies instead of cross-sectional data analysis.

\section{Implications}

\subsection{Implications for Research}

The findings of the research demonstrate mixed results, which contribute theoretically to enhance the knowledge of existing literature on HRM and organizational behavior. In the study, social exchange was defined as the norm of reciprocity relationships which assume that human by nature seeks for reward, they are rational beings, and they have certain standards to evaluate costs and rewards which vary over time and person. The findings of the study empirically support this theory. Particularly, the mediating variable confirms that employees' positive perceptions toward HRM practices i e. staffing, job security, performance appraisal, participation in decision making, and communication and information sharing leads to increase in employee affective commitment. This occurs by the influence or mediating effect of organizational trust and positive opinions of employee regarding the HR practices with the feelings that management has fulfil their responsibility on behalf of the organization. Therefore, in return employees reciprocate behavior motivate them to increase their trust and affective commitment to accomplish organizational success.

\subsection{Implications for Practitioners}

Generally, the findings provide the potential implications for corporate leaders, policy makers, and management practitioners. The study reveals five significance indicators of HRM practices i e. staffing, job security, performance appraisal, participation in decision making, and communication and information sharing are influenced by employees' trust and direct to enhance affective commitment. The findings also be able to identify that reward and compensation are not worth to them to enhance their affiliation toward job. While, the respondent assumed they are depriving to get reward and compensation compares to others banks although they are doing the same profession. Therefore, the study suggests management supposed to be more concern on their reward and compensation packages. In fact, the monitory benefits directly influence employees' perceptions to highly attach with the organization. Trust, motivational power, performance and affiliation toward jobs seem to increase by the factor of reward and compensation systems. Moreover, training system is not adequate to fulfil their job requirements. As a result, they regret that employee training fails to develop organizational trust and affective commitment as well. The study also suggests that regarding training, management have to find out the real needs of training, matching between training programs and trainee. Moreover, a close monitoring system is necessary to monitor overall organizational training system. They can pursue employee training as employee development. Above all, the research findings also aid to enhancing advance skills and knowledge of organizations and professionals' groups by addressing the real scenario of 
present HRM practices. If HR management is agreed with employees' perceptions, then they have to more focus on what will be future action plan and initiatives that supposed to be practices.

\section{Conclusion}

The main objective of this study was to determine the mediating role of organizational trust on the relationships between comprise of HRM practices and affective organizational commitment. The empirical findings confirm staffing, job security, performance appraisal, participation in decision making, and communication and information sharing statistically significant on affective commitment and trust refers to partially mediation. On the other hand, training shows statistically non-significant on the relationship between trust and affective commitment means no mediates.

However, this research was able to point out a new concept that statistically rewards and compensation is significant to trust but non-significant on affective commitment. It suggests for full mediation. Equitable rewards and compensation failed to influence employee affective commitment. Yet, it is positive to organizational trust. As a consequence of social exchange theory human beings are rational, they have certain standards to evaluate cost, labor, and time. Therefore, when employee feels management deprive them in terms of reward and compensation, although other factors are remaining same yet they feel lower and dissatisfaction on affective commitment.

The study recommends that HR management need to treat employees as essential assets to the organization that influence for employees' best performance as potential source of organizational success. Indeed, organizational trust is essential in enhancing the quality of work relationships which effect on organizational environment. The knowledge, reliability, and experience of the management practices may improve trust and affective feelings, emotions, and belongingness. The true sharing of perceptions, feelings of management and giving priority to employee in the decision-making process, unbiased measure of performance appraisal, and the nature of talent hunt motivate employee high trust and high level of affective commitment.

\section{References}

Absar, M. M. N., \& Ahmood, M. (2011). New HRM Practices in the Public and Private Sector Industrial Enterprise of Bangladesh. A comparative Assessment. International Review of Business Research Papers, 7(2), 118-136.

Albrecht, S., \& Travaglione, A. (2003). Trust in Public Sector Senior Management. International Journal of Human Resource Management, 14(1), 76-92. https://doi.org/10.1080/09585190210158529

Azmi, I. A. G. (2010). Competency Based Human Resource Practices in Malaysian Public Sector Organizations. African Journal of Business Management, 4(2), 235-241.

Bangladesh Bank Annual Report: 2011-2012. Online: https://www.bb.org.bd/pub/annual/anreport/ar1112/index1112.php 
Baron, R. M., \& Kenny, D. A. (1986). The Moderator-Mediator Variable Distinction in Social Psychology Research: Conceptual, Strategy, and Statistical Considerations. Journal of $\begin{array}{llrl}\text { Personality and Social } & \text { Psychology, } & \text { 51(6), }\end{array}$ https://doi.org/10.1037/0022-3514.51.6.1173

Bauman, A. E., James, F. S., David, A. D., \& Neville, O. (2002). Toward a Better Understanding of the Influences on Physical Activity: The Role of Determinants, Correlates, Causal Variables, Mediators, Moderators, and Confounders. American Journal of Preventive Medicine, 23(2), 5-14. https://doi.org/10.1016/S0749-3797(02)00469-5

Boselie, P., Hessrlink, M., \& Paauwe, J. (2001). Employee Perception on Commitment Oriented Work Systems: Effects on Trust and Perceived Job Security. Erasmus Research Institute of Management ERS: 2001-02-ORG. Erasmus Universiteit Rotterdam, Netherlands.

Bryman, A., \& Bell, E. (2007). Business Research Methods, 3rd New York: Oxford University Press.

Chapman, R., \& Hyland, P. (2004). Complexity and Learning Behaviors in Product Innovation. Technovation, 24(7), 553-561. https://doi.org/10.1016/S0166-4972(02)00121-9

Charles, A. P. (1969). Convergent and Discriminant Validation of Measures of Personal Needs. Journal of Educational Measurement, 6(2), 103-107. https://doi.org/10.1111/j.1745-3984.1969.tb00666.x

Chiang, H. H., Han, T. S., \& Chuang, J. S. (2011). The Relationship between High Commitment HRM and Knowledge Sharing Behavior and Its Mediators. International Journal of Manpower, 32(5/6), 604-622. https://doi.org/10.1108/01437721111158224

Conway, E., \& Monks, K. (2008). HR Practices and Commitment to Change: An Employee Level Analysis. Human Resource Management Journal, 18(1), 72-89. https://doi.org/10.1111/j.1748-8583.2007.00059.x

Cook, K. S., Cheshire, C., \& Gerbasi, A. (2006). Power, Dependence and Social Exchange. Stanford University Press.

David, M., \& Sutton, C. D. (2004). Social Research: The Basics. SAGE Publication Limited, London.

Fathi, M. A. A., Mohamd, Y., \& Kamal, B. A. (2011). The Mediating Effect of HRM Outcomes (employee retention) on the Relationship between HRM Practices and Organizational Performance. International Journal of Human Resource Studies, 2(1), 75-88.

Ferres, N., \& Travaglione, T. (2003). The Development and Validation of the Workplace Trust Survey (WTS): Combining Quantitative and Qualitative Methodologies. Paper Presented at Development and Validation of the WTS, APROS Mexico.

Field, A. (2005). Discovering Statistics Using SPSS. Book Review, 2nd Edition. London: Sage Publications.

Gong, Y., Law, K. S., Chang, S., \& Xin, K. R. (2009). Human Resource Management and 
Firm Performance: The Differential Role of Managerial Affective and Continuance

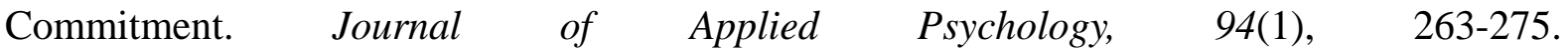
https://doi.org/10.1037/a0013116

Hair, J. F., Black, B., Babin, B. J., \& Anderson, R. E. (2010). Multivariate Data Analysis. A Global Perspective, Seventh Edition, Pearson Prentice Hall.

Han, T. S., Chiang, H. H., \& Chang, A. (2010). Employee Participation in Decision Making, Psychological Ownership and Knowledge Sharing: Mediating Role of Organizational Commitment in Taiwanese High Tech Organizations. International Journal of Human Resource Management, 21(12), 2218-2233. https://doi.org/10.1080/09585192.2010.509625

Huff, L., \& Kelley, L. (2003). Levels of Organizational Trust in Individualist Versus Collectivist Societies: A Seven Nation Study. Organizational Science, 14(1), 81-90. https://doi.org/10.1287/orsc.14.1.81.12807

Hunt, M., Lara, T. M., \& Hughey, A. W. (2009). Establishing and Maintaining Organizational Trust in the 21st Century. Industry of Higher Education, 23(2), 71-77. https://doi.org/10.5367/000000009788146584

Joarder, H. R., \& Sharif, Y. (2012). The Intervening Effects of Affective Commitment on HRM Practices and Turnover Intention Relationship: An Evidence from Non-Western Context. ABAC Journal, 32(1), 16-32.

Joarder, H. R., Sharif, Y., \& Ahmmed, K. (2011). Mediating Role of Affective Commitment in Human Resource Management Practices and Turnover Intention Relationship: A Study in a Developing Context. Business and Economics Research Journal, 2(4), 135-158.

Kingshott, R. P. J., \& Pecotich, A. (2007). The Impact of Psychological Contracts on Trust and Commitment in Supplier Distributor Relationships. European Journal of Marketing, 41(9/10), 1053-1072. https://doi.org/10.1108/03090560710773345

Lamsa, A. M., \& Pucetaite, R. (2006). Development of Organizational Trust among Employees from a Contextual Perspective. Business Ethics: A European Review, 15(2), 130-141. https://doi.org/10.1111/j.1467-8608.2006.00437.x

Lee, K. Y., \& Kim, S. (2010). The Effects of Commitment- Based Human Resource Management on Organizational Citizenship Behaviors: The Mediating Role of the Psychological Contact. World Journal of Management, 2(1), 130-147.

Liu, Y., James, G. C., Ketchen, D. J., \& Duane, R. I. (2007). The Value of Human Resource Management for Organizational Performance. Business Horizons, 50(6), 503-511. https://doi.org/10.1016/j.bushor.2007.07.002

Mayer, R. C., \& Gavin, M. B. (2005). Trust in Management and Performance: Who Minds the Shop while the Employees Watch the Boss? The Academy of Management Journal, 48(5), 874-888. https://doi.org/10.5465/AMJ.2005.18803928

Meyer, J. P., \& Allen, N. J. (1991). A Three Component Conceptualization of Organizational 
Commitment. Human Resource Management Review, 1(1), 61-89. https://doi.org/10.1016/1053-4822(91)90011-Z

Meyer, J. P., \& Smith, C. A. (2000). HRM Practices and Organizational Commitment: Test of a Mediation Model. Canadian Journal of Administrative Sciences, 17(4), 319-331. https://doi.org/10.1111/j.1936-4490.2000.tb00231.x

Morgan, D., \& Zeffane, R. (2010). Employee Involvement, Organizational Change and Trust in Management. The International Journal of Human Resource Management, 14(1), 55-75. https://doi.org/10.1080/09585190210158510

Muller, T. (2008). Living up to One' s Commitments: Agency, Strategies, and Trust. Journal of Applied Logic, 6(2), 251-266. https://doi.org/10.1016/j.jal.2007.06.011

Neves, P., \& Caetano, A. (2009). Commitment to Change: Contributions to Trust in the Supervisor and Work Outcomes. Group \& Organization Management, 34(6), 623-666. Sage Publications. https://doi.org/10.1177/1059601109350980

Newson, R. (2005). Review of Generalized Latent Variable Modeling by Skrondal and Rabe-Hesketh. Stata Journal, 5(1), 130-133.

Nik, M., Nik, A. R., Shahid, S., \& Alam, S. S. (2011). Relationship between Islamic HRM Practices and Employee Commitment: An Empirical Study of Islamic Banks in Bangladesh. Journal of Applied Sciences Research, 7(8), 1269-1278.

Nunnally, J. C. (1978). Psychometric Theory. McGraw-Hill, New York.

Obeidat, Y. B., Masa'deh, R., \& Abdallah, B. A. (2014). The Relationships among Human Resource Management Practices, Organizational Commitment, and Knowledge Management Processes: A Structural Equation Modeling Approach. International Journal of Business and Management, 9(3), 9-26. https://doi.org/10.5539/ijbm.v9n3p9

Pfeffer, J. (2005). Producing Sustainable Competitive Advantage through the Effective Management of People. Academy of Management Executive, 19(4), 95-106. https://doi.org/10.5465/AME.2005.19417910

Pfeffer, J. (2010). Building Sustainable Organizations: The Human Factor. Academy of Management Perspectives, 24(1), 34-45. https://doi.org/10.5465/AMP.2010.50304415

Samuel, M. (1998). Test Validity: A Matter of Consequence. Social Indicators Research, 45(1), 35-44.

Samuel, M., Stefan, C. W., \& Adrian, W. (2009). Apprenticeship Training and the Business Cycle. Empirical Research in Vocational Education and Training, 1(2), 173-186.

Snell, S. A., \& Dean, J. J. W. (1992). Integrated Manufacturing and Human Resource Management: A Human Capital Perspective. Academy of Management Journal, 35(3), 467-504. https://doi.org/10.2307/256484

Snell, S., Belcourt, M., \& Bohlander, G. (2011). Managing Human Resources; Sixth Canadian 
Edition; Nelson Education Ltd.

Storey, J. (2007). Human Resource Management: A Critical Text. Thomson: Third Edition; CengageBrain.com.

Suradi, N. R., Zalina, A., Hafizah, Z. A., \& Norafidah, S. R. (2009). Testing for Mediating Variable in a Regression Model. Int. Conference on Quality, Productivity and Performance Management (ICQPPM). Project Paper: UKM-GPP-PPKK-27-2009.

Tabachnick, B. G., \& Fidell, L. S. (2007). Using Multivariate Statistics. Fifth Edition, New York: Allyn and Bacon Publications.

Tan, F. M. (2008). Organizational Support as the Mediator of Career-Related Human Resource Management Practices and Affective Commitment: Evidence from Knowledge Workers in Malaysia. Research and Practices in Human Resource Management, 16(2), 8-24.

Tan, H. H., \& Lim, A. K. H. (2009). Trust in Co-workers and Trust in Organizations. The Journal of Psychology, 143(1), 45-66. https://doi.org/10.3200/JRLP.143.1.45-66

Tzafrir, S. S., \& Meilik, M. E. (2005). The Impact of Downsizing on Trust and Employee Practices in High Tech Firms: A Longitudinal Analysis. Journal of High Technology Management Research, 16(2), 193-207. https://doi.org/10.1016/j.hitech.2005.10.008

Tzafrir, S. S., Harel, G. H., Baruch, Y., \& Dolan, S. L. (2004). The Consequences of Emerging HRM Practices for Employees' Trust in Their Managers. Personnel Review, 33(6), 628-647. https://doi.org/10.1108/00483480410561529

Wilkinson, A., \& Mellahi, K. (2010). Managing Under Pressure: HRM in Hospitals. Human Resource Management Journal, 20(4), 332-338. https://doi.org/10.1111/j.1748-8583.2010.00145.x

Williams, J. G., \& Davies, F. (2005). Using Social Exchange Theory to Predict the Effects of HRM Practice on Employee Outcomes. Public Management Review, 7(1), 1-24. https://doi.org/10.1080/1471903042000339392

Witte, H. D., \& Naswall, K. (2003). 'Objective' vs 'Subjective' Job Insecurity: Consequences of Temporary Work for Job Satisfaction and Organizational Commitment in Four European Countries. Economic and Industrial Democracy, 24(2), 149-188. https://doi.org/10.1177/0143831X03024002002

Wong, Y. T., Ngo, H. Y., \& Wong, C. S. (2002). Affective Organizational Commitment of Workers in Chinese Joint Ventures. Journal of Managerial Psychology, 17(7), 580-598. https://doi.org/10.1108/02683940210444049

Wright, P. M., \& Kehoe, R. R. (2008). Human Resource Management Practices and Organizational Commitment: A Deeper Examination. Asia Pacific Journal of Human Resources, 46(1), 6-20. https://doi.org/10.1177/1038411107086540.

Yilmaz, K. (2008). The Relationship between Organizational Trust and Organizational Commitment in Turkish Primary Schools. Journal of Applied Science, 8(12), 2293-2299. 
https://doi.org/10.3923/jas.2008.2293.2299

\section{Copyright Disclaimer}

Copyright for this article is retained by the author(s), with first publication rights granted to the journal.

This is an open-access article distributed under the terms and conditions of the Creative Commons Attribution license (http://creativecommons.org/licenses/by/4.0/). 